\title{
OSCILLATION OF $p(x)$-LAPLACIAN ELLIPTIC INEQUALITIES WITH MIXED VARIABLE EXPONENTS
}

\author{
YETER ŞAHINER AND AĞACIK ZAFER
}

Abstract. Oscillation criteria are established for $p(x)$-Laplacian elliptic inequalities with mixed variable nonlinearities of the form

$$
u\left[\nabla \cdot\left(A(x)|\nabla u|^{p(x)-2} \nabla u\right)+\left\langle b(x),|\nabla u|^{p(x)-2} \nabla u\right\rangle-h(x, u)+g(x, u)\right] \leqslant 0, \quad x \in \Omega,
$$

where $\beta(x)>p(x)>\gamma(x)>1, \Omega$ is an exterior domain in $\mathbb{R}^{N}$, and

$$
\begin{aligned}
& h(x, u)=\ln |u||\nabla u|^{p(x)-2}(A(x) \nabla u) \cdot \nabla p(x), \\
& g(x, u)=c(x)|u|^{p(x)-2} u+c_{1}(x)|u|^{\beta(x)-2} u+c_{2}(x)|u|^{\gamma(x)-2} u+f(x) .
\end{aligned}
$$

The function $h(x, u)$ recently introduced in [N. Yoshida, Nonlinear Anal. 74 (2011) 2563-2575] allows employing the Riccati transformation technique commonly used in the oscillation theory of ordinary differential equations.

It should be noted that the results obtained are new for one dimensional case as well. Examples are given to illustrate the results.

Mathematics subject classification (2010): 35B05,34C10.

Keywords and phrases: $p(x)$-Laplacian, oscillation, nonlinear, damped, elliptic equation, second order.

\section{REFERENCES}

[1] N. YoshIDA, Oscillation criteria for half-linear elliptic inequalities with $p(x)$-Laplacians via Riccati method, Nonlinear Anal. 74 (2011), 2563-2575.

[2] N. Yoshida, Picone identities for half-linear elliptic operators with $p(x)$-Laplacians and applications to Sturmian comparison theory, Nonlinear Anal. 74 (2011), 5631-5642.

[3] P. Hartman And A. Wintner, On a comparison theorem for self-adjoint partial differential equations of elliptic type, Proc. Amer. Math. Soc. 6 (1955), 862-865

[4] F. FiEdLER, Oscillation criteria of Nehari-type for Sturm-Liouville operators and elliptic operators of second order and the lower spectrum, Proc. Roy. Soc. Edinb. 109A (1988), 127-144.

[5] J. Jaroš, T. Kusano, AND N. YoshidA, A picone-type identity and Sturmian comparison and oscillation theorems for a class of half-linear partial differential equations of second order, Nonlin. Anal. TMA 40 (2000), 381-395.

[6] O. DošLÝ, R. MǍ̌íK, Nonexistence of positive solutions for PDE's with p-Laplacian, Acta Math. Hungar. 90, 1-2 (2001), 89-107.

[7] H. Us Ami, Some oscillation theorems for a class of quasilinear elliptic equations, Ann. Math. Pura Appl. 175 (1998), 277-283.

[8] R. MǍ̌íK, Ordinary differential equation in the oscillation theory of partial differential equations, J. Math. Anal. Appl. 338 (2008), 194-208.

[9] N. YoshIDA, Forced oscillation criteria for superlinear-sublinear elliptic equations via Picone-type inequality, J. Math. Anal. Appl. 363 (2010), 711-717.

[10] C. A. Swanson, Semilinear second order elliptic oscillation, Canad. Math. Bull. 2, 22 (1979), 139157. 
[11] Z. XU, Oscillation of second order damped elliptic differential equations, Math. Comput. Modelling 47 (2008), 341-351.

[12] R. K. ZHUANG, Annulus oscillation criteria for second order nonlinear elliptic differential equations with damping, Electron. J. Diff. Eqns. 2009 (2009), 1-14.

[13] R. K. ZhuAng, Q. R. Wong AND Z. A. Yao, Some new oscillation theorems for second order nonlinear elliptic equations with damping, J. Math. Anal. Appl. 330 (2007), 622-632.

[14] Y. ŞAHINER, A. ZAFER, Annulus criteria for mixed nonlinear elliptic differential equations, Math. Comput. Modelling 53 (2011), 1856-1864.

[15] G. H. Hardy, J. E. Littlewood, And G. Polya, Inequalities, 2d ed., Cambridge University Press, 1952.

[16] P. Harjulehto, P. Hasto, U. Le, And M. Nuortio, Overwiew of differential equations with non-standard growth, Nonlinear Anal. 72 (2010), 4551-4574.

[17] M. RŮŽIČKA, Electrorheological Fluids: Modeling and Mathematical Theory, in: Lecture Notes in Mathematics 1748 (2000), Springer-Verlag, Berlin.

[18] V. V. ZHIKOv, Averaging of functionals of the calculus of variations and elasticity theory, Math. USSR 29 (1987), 33-66.

[19] C. Alves, Existence of solution for a degenerate $p(x)$-Laplacian equation, J. Math. Anal. Appl. 345 (2008), 731-742.

[20] G. DAI, Infinitely many solution for a $p(x)$-Laplacian equation in $\mathbb{R}^{N}$, Nonlinear Anal. 71 (2009), 1133-1139.

[21] Y. FU, X. Zhang, A multiplicity result for $p(x)$-Laplacian problem in $\mathbb{R}^{N}$, Nonlinear Anal. 70 (2009), 2261-2269.

[22] Q. H. ZHANG, Existence of radial solutions for $p(x)$-Laplacian equations, J. Math. Anal. Appl. 315 (2006), 506-516.

[23] J. CHABRowSKI, Y. FU, Existence of solutions for the $p(x)$-Laplacian problems on a bounded domain, J. Math. Anal. Appl. 306 (2005), 604-618.

[24] QIHU ZHANG, Existence and asymptotic behavior of positive solutions for variable exponent elliptic systems, Nonlinear Anal. 70 (2009), 305-316.

[25] QIHU Zhang, Zhimei QUi, AND RONG Dong, Existence and asymptotic behavior of positive solutions for a variable exponent elliptic system without variational structure, Nonlinear Anal. 72 (2010), 354-363.

[26] R. MAŘík, Oscillation Theory of Partial Differential Equations with p-Laplacian, Folia. Univ. Agric. et Silvic. Mendel. Brun., Brno(2008).

[27] D.Gilbarg And N.S.Trudinger, Elliptic Partial Differential Equations of Second Order, Springer-Verlag, New York, 1983.

[28] N. Yoshida, Oscillation Theory of Partial Differential Equations, World Scientific Publishing Co. Pte. Ltd., 2008.

[29] W. Allegretto, Form estimates for the $p(x)$-Laplacian, Proc. Amer. Math. Soc. 135 (2007), $2177-$ 2185.

[30] E.S. NousS AIR AND C. A. SWANSON, Oscillation of semilinear elliptic inequalities by riccati transformation, Canad. J. Math. 4, 32 (1980), 908-923.

[31] Y. G. Sun AND J.S.W. Wong, Oscillation criteria for second order forced ordinary differential equations with mixed nonlinearities, J. Math. Anal. Appl. 334 (2007), 549-560. 